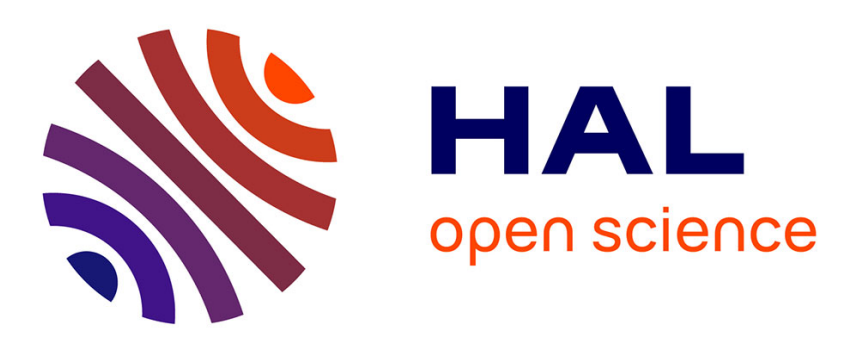

\title{
Bipolar self-doping in ultra-wide bandgap spinel $\mathrm{ZnGa2O4}$
}

Z. Chi, Fu-Gow Tarntair, M. Frégnaux, Wan-Yu Wu, C. Sartel, I. Madaci, P. Chapon, V. Sallet, Y. Dumont, A. Pérez-Tomás, et al.

\section{> To cite this version:}

Z. Chi, Fu-Gow Tarntair, M. Frégnaux, Wan-Yu Wu, C. Sartel, et al.. Bipolar selfdoping in ultra-wide bandgap spinel ZnGa2O4. Materials Today Physics, 2021, 20, pp.100466. 10.1016/j.mtphys.2021.100466 . hal-03408217

\section{HAL Id: hal-03408217 https://hal.science/hal-03408217}

Submitted on 9 Nov 2021

HAL is a multi-disciplinary open access archive for the deposit and dissemination of scientific research documents, whether they are published or not. The documents may come from teaching and research institutions in France or abroad, or from public or private research centers.
L'archive ouverte pluridisciplinaire HAL, est destinée au dépôt et à la diffusion de documents scientifiques de niveau recherche, publiés ou non, émanant des établissements d'enseignement et de recherche français ou étrangers, des laboratoires publics ou privés. 


\title{
Bipolar Self-doping in Ultra-wide Bandgap Spinel $\mathrm{ZnGa}_{2} \mathrm{O}_{4}$
}

\author{
Z. Chi ${ }^{1}$, Fu-Gow Tarntair ${ }^{2}$, M. Frégnaux ${ }^{3}$, Wan-Yu Wu ${ }^{4}$, C. Sartel ${ }^{1}$, I. Madaci ${ }^{1}$, P. Chapon ${ }^{5}$, \\ V.Sallet $^{1}$, Y. Dumont ${ }^{1}$, A. Pérez-Tomás ${ }^{6}$, R.H. Horng ${ }^{2}$, E. Chikoidze ${ }^{1}$ \\ ${ }^{1}$ Groupe d'Etude de la Matière Condensée (GEMaC), Université Paris-Saclay, Université de Versailles Saint \\ Quentin en Yvelines - CNRS, 45 Av. des Etats-Unis, 78035 Versailles Cedex, France \\ ${ }^{2}$ Institute of Electronics, National Yang Ming Chiao Tung University, Hsinchu 30010, Taiwan, ROC \\ ${ }^{3}$ Institut Lavoisier de Versailles (ILV), Université Paris-Saclay, Université de Versailles Saint Quentin en \\ Yvelines - CNRS, 45 Av. des Etats-Unis, 78035 Versailles Cedex, France \\ ${ }^{4}$ Department of Materials Science and Engineering, Da-Yeh University, Changhua 51591, Taiwan \\ ${ }^{5}$ Horiba Jobin Yvon SAS, Bd Thomas Gobert, 91120 Palaiseau, France \\ ${ }^{6}$ Catalan Institute of Nanoscience and Nanotechnology (ICN2), CSIC and The Barcelona Institute of Science \\ and Technology, Barcelona, Spain
}

Corresponding authors: ekaterine.chikoidze@uvsq.fr; rhh@nctu.edu.tw

Keywords: Ultra-wide bandgap oxide, $\mathrm{ZnGa}_{2} \mathrm{O}_{4}$, conductivity, point defects

\begin{abstract}
The spinel group is a growing family of materials with general formulation $\mathrm{AB}_{2} \mathrm{X}_{4}$ (the $\mathrm{X}$ anion typically being a chalcogen like $\mathrm{O}$ and $\mathrm{S}$ ) with many advanced applications for energy. At the time being, the spinel zinc gallate $\left(\mathrm{ZnGa}_{2} \mathrm{O}_{4}\right)$ arguably is the ternary ultra-wide bandgap bipolar oxide semiconductor with the largest bandgap $(\sim 5 \mathrm{eV})$, making this material very promising for implementations in deep UV optoelectronics and ultra-high power electronics. In this work, we further demonstrate that, exploiting the rich cation coordination possibilities of the spinel chemistry, the $\mathrm{ZnGa}_{2} \mathrm{O}_{4}$ intrinsic conductivity (and its polarity) can be controlled well over 10 orders of magnitude. $p$-type and $n$-type $\mathrm{ZnGa}_{2} \mathrm{O}_{4}$ epilayers can be grown by tuning the pressure, oxygen flow and cation precursors ratio during metal-organic chemical vapor deposition. A relatively deep acceptor level can be achieved by promoting antisites $\left(\mathrm{Zn}_{\mathrm{Ga}}\right)$ defects, while up to a $\left(n>10^{19} \mathrm{~cm}^{-3}\right)$ donor concentration is obtained due to the hybridization of the $\mathrm{Zn}-\mathrm{O}$ orbitals in the samples grown in Zn-rich conditions. Electrical transport, atomic and optical spectroscopy reveal a free hole conduction (at high temperature) for $p-\mathrm{ZnGa}_{2} \mathrm{O}_{4}$ while for $n-\mathrm{ZnGa}_{2} \mathrm{O}_{4}$ a (Mott) variable range hopping (VRH) and negative magnetoresistance phenomena take place, originated from "self-impurity" band located at Ev+ $\sim 3.4 \mathrm{eV}$. Among arising ultra-wide bandgap semiconductors, spinel $\mathrm{ZnGa}_{2} \mathrm{O}_{4}$ exhibit unique self-doping capability thus extending its application at the very frontier of current energy optoelectronics.
\end{abstract}




\section{Introduction}

Ultra-wide bandgap (UWBG) semiconductor oxides have recently rejuvenated [1,2] and are now attracting considerable interest as an advanced platform for energy electronics, including deep UV optoelectronics and power devices owing to their ultra-high critical electric field [3], control of the electrical conductivity, chemical stability and the possibility of grown large single crystals (up to 6-inch) at a reduced cost (i.e., Silicon-like Czochralski (CZ) method) [4]. The binary oxide semiconductor gallium oxide $\left(\mathrm{Ga}_{2} \mathrm{O}_{3}\right)$ ( $\mathrm{E}_{\text {gap }} \sim 4.6-4.9 \mathrm{eV}$ ) is somehow heralding this emerging field, but complex gallium oxide alloys are widely investigated in particular $\mathrm{Ga}_{2} \mathrm{O}_{3}: \mathrm{Al}_{2} \mathrm{O}_{3}$ [5] and $\mathrm{Ga}_{2} \mathrm{O}_{3}: \mathrm{ZnO}$ [6]. While corundum $\mathrm{Ga}_{2} \mathrm{O}_{3}: \mathrm{Al}_{2} \mathrm{O}_{3}$ alloys have resulted in a successful route to further enlarge the bandgap of $\mathrm{Ga}_{2} \mathrm{O}_{3}$ [5] and to create a two-dimensional electron gas (2DEG) at the $\mathrm{GaO} / \mathrm{AlGaO}$ interface [7], the alloy of $\mathrm{Ga}_{2} \mathrm{O}_{3}$ and $\mathrm{ZnO}$ can be stabilized in the energy electronics relevant spinel phase of Zinc Gallate $\left(\mathrm{ZnGa}_{2} \mathrm{O}_{4}\right)$ with an optical bandgap of $\sim 5 \mathrm{eV}[8,9]$. Indeed, spinel $\mathrm{ZnGa}_{2} \mathrm{O}_{4}$ thin films (which, very relevant from the practical point of view, can be easily and directly grown epitaxially on cheap sapphire substrates), have been recently investigated for photonics (phosphors [10,11], deep-ultraviolet photodetectors [9], phototransistors [12-14]), gas sensors [15] or power thin-film-transistors (PTFTs) [16,17]. In many of these promising applications, the control of the $\mathrm{ZnGa}_{2} \mathrm{O}_{4}$ conductivity is a central issue. In simple binary oxides, the intrinsic conductivity or self-doping is usually achieved by vacancies or interstitials; oxygen vacancies and cation interstitials result in $n$-type doping, while cation vacancies result in acceptor $p$-type doping. Many transparent conducting oxides are well-known electron transport layers (notably donor doped of $\mathrm{ZnO}, \mathrm{SnO}_{2}$ and $\mathrm{In}_{2} \mathrm{O}_{3}$ ) for their propensity to create oxygen vacancies. However, bipolar junction-based electronics requires the development of both $n$ - and $p$-type semiconductor materials. Indeed, ultra-wide bandgap $n$-type doped binary oxides are already well developed $[18,19]$, but, due to high formation energy and large ionization energy of native acceptors, and low formation energy of native hole killer [20], $p$-type conductivity in wide and ultra-wide binary oxides, is usually very challenging.

Spinel oxides generally refer to the compound with the formulation of $\mathrm{AB}_{2} \mathrm{O}_{4}$, where $\mathrm{A}$ and $\mathrm{B}$ are either II-valent and III-valent or IV-valent and II-valent metal cations, respectively. Arranging a close-packed facecentred cubic crystal structure $(\mathrm{Fd} 3 \mathrm{~m})$, in an ordered-normal phase, the oxygen ions in such $\mathrm{AB}_{2} \mathrm{O}_{4}$ materials form tetrahedral $\left(T_{d}\right)$ sites where 1/8 occupied by all A cations, whereas the entire $B$ cations reside in one-half of octahedral $\left(\mathrm{O}_{\mathrm{h}}\right)$ sites. In this case, a stable octet, so-called closed-shell, is made up of the $\mathrm{AB}_{2} \mathrm{O}_{4}$ system, it then leads to an electrical insulator behavior [21]. However, the distribution of cations in $T_{d}$ and $\mathrm{O}_{\mathrm{h}}$ sites is dependent on several factors, such as impurities [22,23] and preparation methods [24,25]. Therefore, the disorder distribution of cations could result in additional routes for self-doping effects. According to a number of theoretical works, spinel oxides are well-known to have inverted distribution of cations caused by antisite defects [26-29], which could improve its conductivity [21,28,30-32]. This selfdoping effect could release us from the doping difficulty what is often very challenging in binary widebandgap oxides, but $n$-type conductivity requires more low-valent atoms and fewer high-valent atoms than stoichiometric compounds (e.g. $\mathrm{Zn} / \mathrm{Ga}>1 / 2$ in $\mathrm{ZnGa}_{2} \mathrm{O}_{4}$ ), or vice versa. Although optical properties of 
$\mathrm{ZnGa}_{2} \mathrm{O}_{4}$ were intensively studied [33], little is known about the mechanism and the origin of its $p$ - and $n$ type electrical conductivity.

In general, and as natural for an ultra-wide bandgap oxide representative with its Fermi level lying near the mid-gap, poor conductivity (if any) has been found for undoped as-grown $\mathrm{ZnGa}_{2} \mathrm{O}_{4}$ thin films [34-36]. However, high electron conductivity was already reported in the past for hydrogen annealed $\mathrm{ZnGa}_{2} \mathrm{O}_{4}$ thin films [35,37]. Besides, intrinsic donor electron conductivity has also very recently been reported for some bulk blue colored crystals [38] thin films grown by pulsed laser deposition (PLD) [39], and metal-organic chemical vapor deposition (MOCVD) [16]. In these conducting ultra-wide transparent conducting oxides (TCOs), different electron concentrations ranging from $5.9 \times 10^{16} \mathrm{~cm}^{-3}[17,34,40]$ to $6.16 \times 10^{19} \mathrm{~cm}^{-3}[39]$ have been reported. The $n$-type conductivity was usually explained by the presence of oxygen vacancies [35$37,41]$, but they are well-known to arguably be deep centres in $\mathrm{ZnGa}_{2} \mathrm{O}_{4}[21,28,42]$. In the same way, it has also been demonstrated a native high-temperature $p$-type conductivity for $\mathrm{ZnGa}_{2} \mathrm{O}_{4}$ thin films elaborated by MOCVD [43]. Although these observations and that a bunch of theoretical works deals with the issue $[29,44,45]$, the actual phenomenological origin and mechanisms of the $\mathrm{ZnGa}_{2} \mathrm{O}_{4}$ spinel self-doping remain elusive. Here, we aim to shed light on the UWBG self-doping nature by a comparative analysis of native acceptor and donor spinel gallate by a range of spectroscopic and transport measurement techniques. Our results, further reinforce the fact that $\mathrm{ZnGa}_{2} \mathrm{O}_{4}$ has unique bipolar prospects among currently known UWBG oxides and point out exotic and mostly unexplored origin of $p$-type and $n$-type based on antisites states and a defective band due to $\mathrm{Zn}-\mathrm{O}$ hybridization within its ultra-large bandgap, respectively.

\section{Structural studies of $n$-type and $p$-type $\mathrm{ZnGa}_{2} \mathrm{O}_{4}$ thin films}

The $\mathrm{ZnGa}_{2} \mathrm{O}_{4}$ samples were grown in a RF-heated horizontal MOCVD reactor on $c$-oriented sapphire $\left(\mathrm{Al}_{2} \mathrm{O}_{3}\right)$ substrates, as described in methods. The different conductivity values and conductivity types are achieved by tuning the pressures, the cation precursors Diethylzinc (DEZn)/Triethylgallium (TEGa) ratios and growth temperatures. Details are described in methods. The XRD spectra between 15 and $65^{\circ}$ (FIG.1-a) show that both acceptor and donor $\mathrm{ZnGa}_{2} \mathrm{O}_{4}$ thin films are very similar by structural properties. The $3 \mathrm{Bragg}$ peaks of the as-grown $n$-type layer are at $2 \theta$ values of $18.47^{\circ}, 37.40^{\circ}, 57.50^{\circ}$, while those of $p$-type film are at $2 \theta$ values of $18.45^{\circ}, 37.42^{\circ}, 57.56^{\circ}$. These 3 peaks correspond to the $\{111\}$ plane family, their indexes in Fd3m space group are (111), (222), and (333), respectively. Additionally, the corresponding lattice parameter of $n-\mathrm{ZnGa}_{2} \mathrm{O}_{4}$ films is estimated to be $8.32 \AA$ while it is $8.33 \AA$ for $p-\mathrm{ZnGa}_{2} \mathrm{O}_{4}$ films. Elemental depth profiles of the $\mathrm{ZnGa}_{2} \mathrm{O}_{4}$ samples were obtained by glow discharge optical emission spectroscopy (GDOES), as shown in the insert of FIG.1-b. 

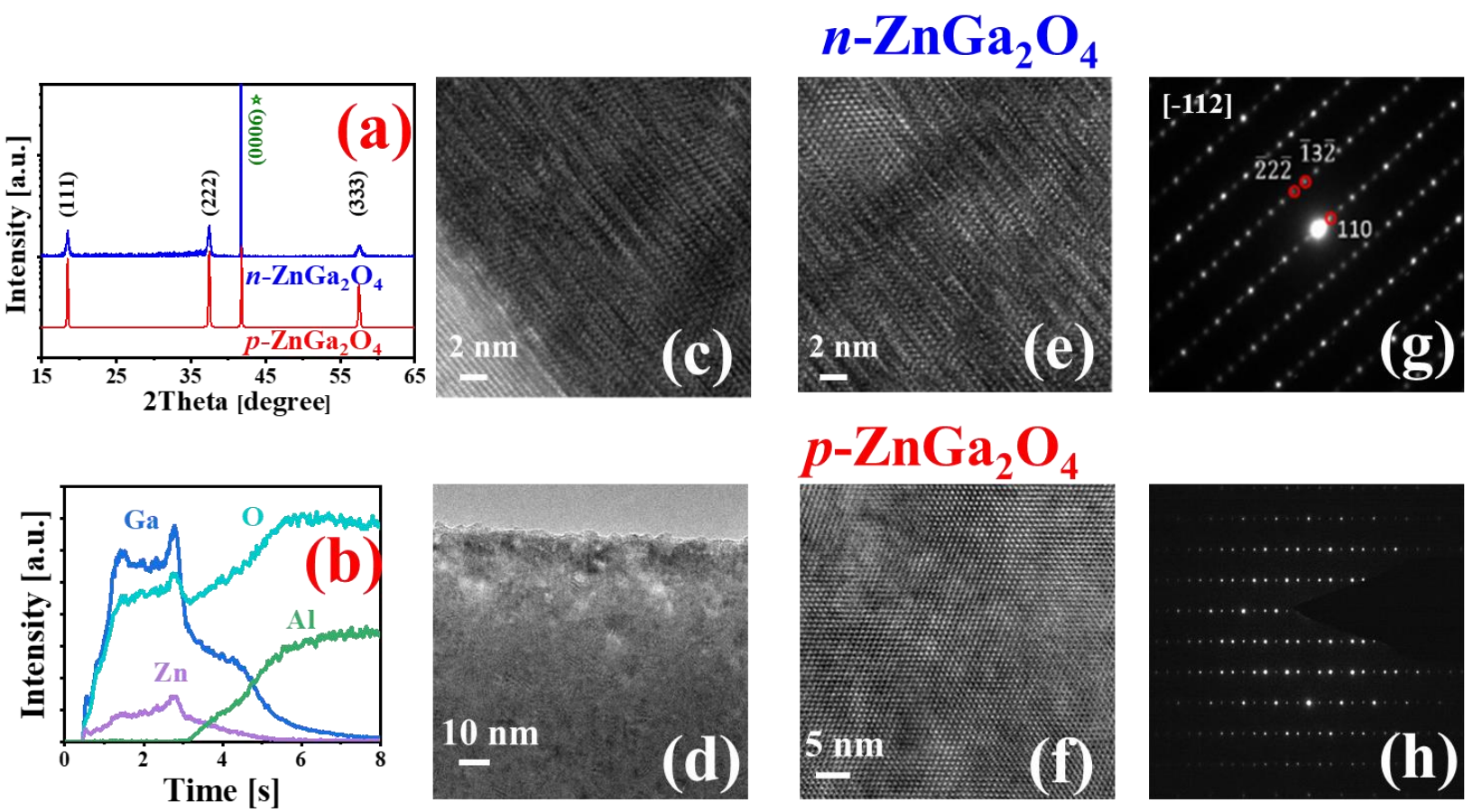

Fig.1. (a) X-ray diffractograms of as-grown $n$-type and $p$-type $\mathrm{ZnGa}_{2} \mathrm{O}_{4}$ thin films grown (0006) sapphire (intensity in log scale); the peak labelled by " $\star$ " indicates the XRD reflection corresponding to the sapphire substrate. (b) GDOES depth profile Transmission electron microscope (TEM) images for (c) $n$-type $\mathrm{ZnGa}_{2} \mathrm{O}_{4}$ thin film and (d) $p$-type $\mathrm{ZnGa}_{2} \mathrm{O}_{4}$ thin film. High resolution (HR) TEM images are shown in (e) and (f), for $n$-type and $p$-type $\mathrm{ZnGa}_{2} \mathrm{O}_{4}$, respectively. (g) SAED images of $n-\mathrm{ZnGa}_{2} \mathrm{O}_{4}$ and $p-\mathrm{ZnGa}_{2} \mathrm{O}_{4}$.

The TEM analysis used SAED (selected area electron diffraction) for $n$-type and $p$-type $\mathrm{ZnGa}_{2} \mathrm{O}_{4}$ thin films are shown in FIG.1. Both $n$-type and $p$-type $\mathrm{ZnGa}_{2} \mathrm{O}_{4}$ exhibited a high-quality epitaxial single crystal structure as shown in interface images FIG.1-c, -e, and in FIG.1-c, -f, respectively. The high-resolution image in Fig.1-e demonstrates strain accompany by the dislocation within the two areas. The dislocation belongs to a stacking fault on the (110) plane of $n$-type $\mathrm{ZnGa}_{2} \mathrm{O}_{4}$ thin film according to FIG.1-g. The $n$-type and $p$-type $\mathrm{ZnGa}_{2} \mathrm{O}_{4}$ oriented [-112] and [011] are shown in FIG.1-g and -h, respectively.

\section{Electronic structure of $\boldsymbol{n}$-type and $p$-type $\mathrm{ZnGa}_{2} \mathrm{O}_{4}$ thin films}

In addition to surface elemental composition, the x-ray photoelectron spectroscopy (XPS) provide information of $\mathrm{Ga}, \mathrm{Zn}$ and $\mathrm{O}$ local bonding environment as well as the chemical state for the different $n$ - and $p-\mathrm{ZnGa}_{2} \mathrm{O}_{4}$ surfaces. The shift of local atomic binding energies is attributable to the cation formal oxidation state, the identity of its nearest-neighbor ( $\mathrm{Ga}$ or $\mathrm{Zn}$ ) and its bonding hybridization. As recently reminded by De Souza et al.[46] and Walsh et al. [47], the XPS element binding energy in a solid are governed not only by the parent atom but also by the atomic arrangement in the compound. Adventitious carbon contamination C1s at 284,8 eV (FIG.2-d) was used as calibration for all the spectra in the absence of a better procedure [48]. One first observation is that, regardless of whether is $n$ - or $p-\mathrm{ZnGa}_{2} \mathrm{O}_{4}$, the $\mathrm{Ga}$ and $\mathrm{Zn}$ core level binding energies (BEs) are larger for spinel $\mathrm{ZnGa}_{2} \mathrm{O}_{4}$ (the complex oxide from binary $\mathrm{Ga}_{2} \mathrm{O}_{3}: \mathrm{ZnO}$ ) than for either, reference monoclinic $\beta$ - $\mathrm{Ga}_{2} \mathrm{O}_{3}$ (p-type) and wurtzite $\mathrm{ZnO}$ ( $n$-type), which is a result consistent with previous 
literature. It is customary to attribute the cation's shift towards higher binding energies to larger oxidation states although, in theory, the $\mathrm{Zn}^{2+}$ and $\mathrm{Ga}^{3+}$ are in the same oxidation state in $\mathrm{ZnGa}_{2} \mathrm{O}_{4}, \mathrm{Ga}_{2} \mathrm{O}_{3}$ and $\mathrm{ZnO}$. For example, the $\mathrm{Ga} 2 p_{3 / 2}$ peak in reference monoclinic $\mathrm{Ga}_{2} \mathrm{O}_{3}$ appears at a smaller binding energy of $1117.6 \mathrm{eV}$ which perhaps may be understood because of the reduced coordination of half of the metal ions. There are two kinds of coordination for $\mathrm{Ga}^{3+}$ ions in $\beta-\mathrm{Ga}_{2} \mathrm{O}_{3}$ structure, namely tetrahedral and octahedral which average inter-ionic distances are, $T_{d} \mathrm{Ga}-\mathrm{O}=1.83 \AA \mathrm{O}-\mathrm{O}=3.02 \AA$ and $O_{h} \mathrm{Ga}-\mathrm{O}=2.00 \AA \mathrm{O}-\mathrm{O}=2.84 \AA$ [49]. The inter-ionic distances for $\mathrm{ZnGa}_{2} \mathrm{O}_{4}$ are $T_{d} \mathrm{Zn}-\mathrm{O}=1.95 \AA$ and $O_{h} \mathrm{Ga}-\mathrm{O}=2.00 \AA$, respectively [50]. All the $\mathrm{Zn}-\mathrm{O}$ bonds are tetrahedral for both, normal $\mathrm{ZnGa}_{2} \mathrm{O}_{4}$ and reference wurtzite $\mathrm{ZnO}$ where $\mathrm{Zn}-\mathrm{O}$ bond lengths are usually reported to be $T_{d} \mathrm{Zn}-\mathrm{O} \sim 2.0 \AA$ ( $\mathrm{Zn}-\mathrm{Zn} / \mathrm{O}-\mathrm{O} \sim 3.2 \AA$ ).

Focusing on the $\mathrm{ZnGa}_{2} \mathrm{O}_{4}$ samples, the $\mathrm{Ga} 2 p_{3 / 2}$ (FIG.2-a) and $\mathrm{Zn} 2 p_{3 / 2}$ (FIG.2-c) peaks appear at 1118.2 $\mathrm{eV}$ and $1022.2 \mathrm{eV}$ for $p-\mathrm{ZnGa}_{2} \mathrm{O}_{4}$ and at $1118.1 \mathrm{eV}$ and $1022.0 \mathrm{eV}$ for $n-\mathrm{ZnGa}_{2} \mathrm{O}_{4}$, respectively. Therefore, it can be concluded that the effect of self-doping in the $\mathrm{ZnGa}_{2} \mathrm{O}_{4}$ cation's shift on $\mathrm{Zn} 2 p(\Delta \mathrm{BE} \sim 0.2 \mathrm{eV})$ and $\mathrm{Ga} 2 p\left(\Delta \mathrm{BE} \sim 0.1 \mathrm{eV}\right.$ ) is rather small (when compared with the $\mathrm{ZnGa}_{2} \mathrm{O}_{4}$ vs $\mathrm{Ga}_{2} \mathrm{O}_{3}$ or $\mathrm{ZnO}$ energy shifts $\Delta \mathrm{BE}$ $\sim 0.7 \mathrm{eV}$ ). In contrast to simple binary oxides, where dominant defects are vacancies and interstitials, dominant defects in spinels are suggested to be antisites [30,31]. These antisites are donor $(\mathrm{Gazn})$ [donor-like $\mathrm{Ga}^{3+}\left(\mathrm{O}_{\mathrm{h}}\right)$-on- $\mathrm{T}_{\mathrm{d}}$ antisite defects] and acceptor $\left(\mathrm{Zn}_{\mathrm{Ga}}\right)$ [acceptor-like $\mathrm{Zn}^{2+}\left(\mathrm{T}_{\mathrm{d}}\right)$-on- $\mathrm{O}_{\mathrm{h}}$ antisite defects]. The degree of inversion in zinc gallate has been estimated by the deconvolution of the Ga2 $p$ and Zn2 $p$ XPS peaks in two components at different binding energies (BEs) [24]. For $p-\mathrm{ZnGa}_{2} \mathrm{O}_{4}, \mathrm{Ga}_{2} p_{3 / 2}$ and peak appears at $1118.2 \mathrm{eV}$. By deconvolution, a normal $\mathrm{Ga}^{3+}\left(\mathrm{O}_{\mathrm{h}}\right)$ and an inversion $\mathrm{Ga}^{3+}(\mathrm{Td})$ appear at $1118.3 \mathrm{eV}$ and 1116.8 $\mathrm{eV}$, respectively. Whereas a $\mathrm{Zn} 2 p_{3 / 2}$ normal $\mathrm{Zn}^{2+}\left(\mathrm{T}_{\mathrm{d}}\right)$ and an inversion $\mathrm{Zn}^{2+}\left(\mathrm{O}_{\mathrm{h}}\right)$ are at $\sim 1022 \mathrm{eV}$ and $\sim 1023$ $\mathrm{eV}$, respectively. The inversion sites $\mathrm{Zn}_{\mathrm{Ga}}$ and $\mathrm{Ga}_{\mathrm{Zn}}$ take $\sim 5.3 \%$ and $\sim 2.8 \%$ of the total area of $\mathrm{Zn} 2 p_{3 / 2}$ and $\mathrm{Ga} 2 p_{3 / 2}$, respectively [43]. Nevertheless, the binding energy curve of $\mathrm{Zn} 2 p$ and $\mathrm{Ga} 2 p$ of $n-\mathrm{ZnGa}_{2} \mathrm{O}_{4}$ is well symmetric, indicating a unique chemical contribution on each atomic binding energy implying that the antisite defects are either, too few to be detected or inexistent. This already suggests a different origin for the self-doping in the case of donors and acceptors.

Regarding the anion (oxygen O1s) as shown in FIG.2-b, the metal oxide oxygen peak binding energy in $\mathrm{ZnO}(\sim 530 \mathrm{eV})$ (e.g. [51]) and that in spinel $\mathrm{ZnGa}_{2} \mathrm{O}_{4}(\sim 531 \mathrm{eV})$ have a notable difference. In contrast, the metal oxide peak in $\mathrm{ZnGa}_{2} \mathrm{O}_{4}$ and $\mathrm{Ga}_{2} \mathrm{O}_{3}$ appears at the same energy $(\sim 531 \mathrm{eV})$. There is also a clear difference in the $\mathrm{O} 1 \mathrm{~s}$ shoulder features between $n-\mathrm{ZnGa}_{2} \mathrm{O}_{4}$ and $p-\mathrm{ZnGa}_{2} \mathrm{O}_{4}$ which is clearly visible for $n$ $\mathrm{ZnGa}_{2} \mathrm{O}_{4}$ (as for $\mathrm{n}-\mathrm{ZnO}$ ) and much smaller for $p-\mathrm{ZnGa}_{2} \mathrm{O}_{4}$ (as for $\mathrm{p}-\mathrm{Ga}_{2} \mathrm{O}_{3}$ ). Interestingly, the most notable difference between $n$-type and $p$-type $\mathrm{ZnGa}_{2} \mathrm{O}_{4}$ precisely is found in the shape of the $\mathrm{O} 1 s$. A double feature at higher binding energy can be seen clearly in the $n-\mathrm{ZnGa}_{2} \mathrm{O}_{4}$ peak, suggesting $\mathrm{O}^{2-}$ and $\mathrm{O}^{-}$components. In zinc oxide thin films (but also in many other metal-oxide semiconductors), this oxygen shoulder ( $\left.\mathrm{O}_{\mathrm{II}}\right)$ has been related to hydroxide [52], hydrate [53] or oxygen deficiency [54]. Wu et al. [55] suggested that $\mathrm{O}_{\mathrm{s}} \mathrm{O}_{\mathrm{I}} / \mathrm{O}_{\mathrm{II}}$ ratio may be regarded as a general experimental method for estimating the ionicity and average valence of oxygen anions. The absence of shoulder features in $p-\mathrm{ZnGa}_{2} \mathrm{O}_{4}$ and $p-\mathrm{Ga}_{2} \mathrm{O}_{3} \mathrm{O} 1 \mathrm{~s}$ may be correlated with a lower donor compensation (e.g. very low concentration of oxygen vacancies). In $n$-type $\mathrm{ZnGa}_{2} \mathrm{O}_{4}$, the $\mathrm{O} 1 s$ 
lattice peak appears at $530.9 \mathrm{eV}$, and the shoulder maxima was found at $532.1 \mathrm{eV}$ (FIG.2-e). Again, according to the interpretation proposed by Dupin et al. $[55,56]$, the lower $\mathrm{BE}$ peak is assigned to $\mathrm{O}^{2-}$ ions, the middle $\mathrm{BE}$ peak to $\mathrm{O}^{1-}$ ions, and the higher $\mathrm{BE}$ peak to $\mathrm{O}_{\mathrm{Chem}}$, chemically adsorbed oxygen on the surface. From the relative peak areas of the main components, it can be deduced that the content ratio between $\mathrm{O}^{1-}$ ions and $\mathrm{O}^{2-}$ ions is approximately equal to $0.40 / 0.60$ (neglecting the chemically adsorbed oxygen on the surface). Therefore, it can be estimated an average valence of the $\mathrm{O}$ anion for $n-\mathrm{ZnGa}_{2} \mathrm{O}_{4}$ of $\sim-1.6$, while it is $\sim-2.0$ for $p-\mathrm{ZnGa}_{2} \mathrm{O}_{4}$ (i.e., very close to its nominal value). Therefore, $n-\mathrm{ZnGa}_{2} \mathrm{O}_{4}$ would deviate from the fully ionic picture. In the ionic limit, the charge of the ion is its formal charge; if an oxygen ion in an oxide has a charge of $-2 \mathrm{e}$, the relative charge of an oxygen vacancy is $q_{\text {real }}-q_{\text {ideal }}=0 \mathrm{e}-(-2 \mathrm{e})=+2 \mathrm{e}$. However, even for oxides that are not fully ionic, the oxygen vacancy is still considered universally to possess a relative charge of $+2 \mathrm{e}$ [46]. In any case, based on the observables, the degenerated $n$-type $\mathrm{ZnGa}_{2} \mathrm{O}_{4}$ doping has a minimum impact on core $\mathrm{Ga} 2 p$, a moderate impact on core $\mathrm{Zn} 2 p$, and, a clear impact on the core O1s shoulder features. A simple coherent explanation with these facts implies Ga vacancies and modified Zn-O hybridization. XPS atomic quantification suggests an oxygen-deficient scenario with oxygen/metal ratio of $\sim 1$, and, perhaps more trustable, $\mathrm{Ga} / \mathrm{Zn}$ was determined to be $\sim 1.9$, revealing the Zinc-rich condition of $n-\mathrm{ZnGa}_{2} \mathrm{O}_{4}$. However, recall again that no signature of $\mathrm{ZnO}$ has been found structurally either by XRD or by TEM analysis and that $n-\mathrm{ZnGa}_{2} \mathrm{O}_{4}$ is considered a pure spinel in nature.

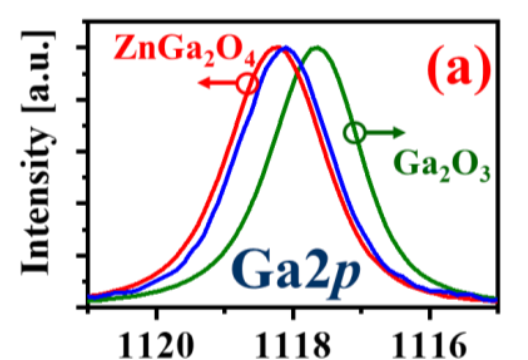

Binding Energy [eV]

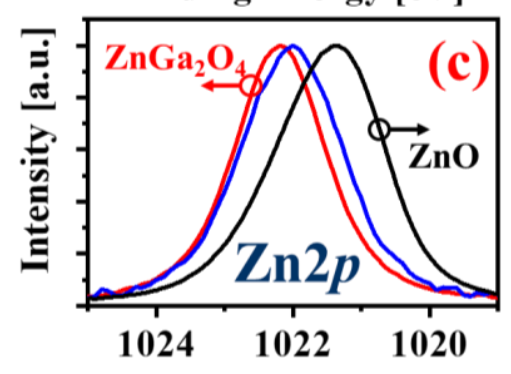

Binding Energy [eV]

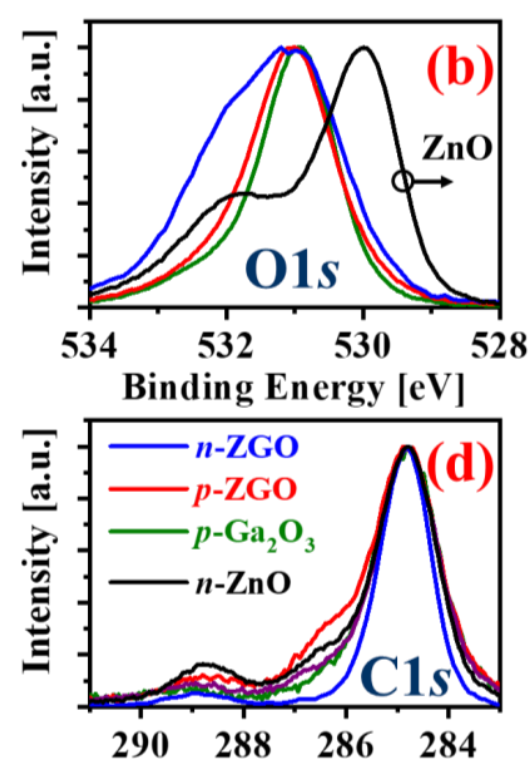

Binding Energy [eV]

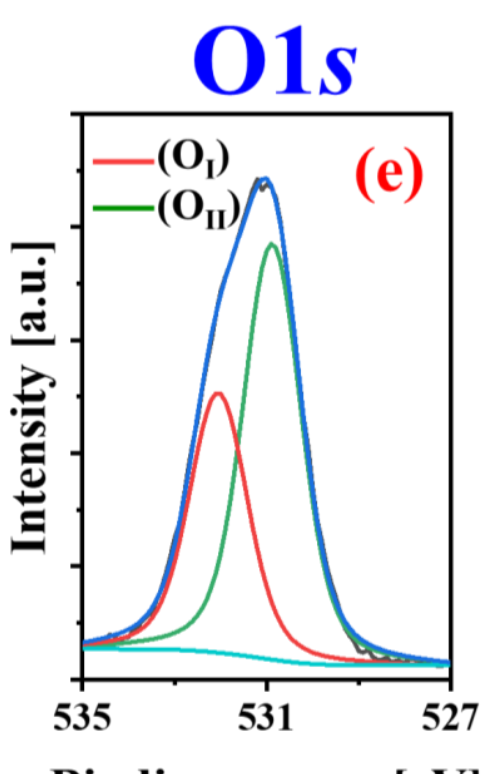

Binding energy $[\mathrm{eV}]$

Fig.2. Detail (intensity normalized) of the main XPS peaks for (a) gallium (Ga2p- Ga2p $3 / 2$ ), (b) oxygen $(\mathrm{O} 1 s)$, (c) zinc $\left(\mathrm{Zn} 2 p-\mathrm{Zn} 2 p_{3 / 2}\right)$, (d) adventitious carbon contamination (C1s, calibration for C-C bonds at $284.8 \mathrm{eV}$ ) of $n$-type $\mathrm{ZnGa}_{2} \mathrm{O}_{4}$, pure $\beta$ - $\mathrm{Ga}_{2} \mathrm{O}_{3}$, pure wurtzite $\mathrm{ZnO}$ and $p$-type $\mathrm{ZnGa}_{2} \mathrm{O}_{4}$ (ZGO) for comparison.

(e) Deconvolution of the main contributions of the O1s oxygen peak for spinel $\mathrm{ZnGa}_{2} \mathrm{O}_{4}$. 


\section{Valence Band and Optical Bandgap of $n$-type and $p$-type $\mathrm{ZnGa}_{2} \mathrm{O}_{4}$ thin films}

Let us now focus on the experimental valence band features extracted from the XPS analysis, as shown in Fig.3. All the valence band edge has been shifted using the adventitious C-C $284.8 \mathrm{eV}$ following the same procedure as with the core levels (FIG.2-c). The experimental valence band width of the $\mathrm{ZnGa}_{2} \mathrm{O}_{4}$ thin films is around $\sim 8 \mathrm{eV}$, having to main contributions; the top of the valence (lower binding energies) is ascribed to $\mathrm{O} 2 p$ states while there is an important contribution at larger binding energies due to $\mathrm{Zn} 3 d$ states peaking at $10.8 \mathrm{eV}\left(n-\mathrm{ZnGa}_{2} \mathrm{O}_{4}\right)$ and $8.2 \mathrm{eV}\left(p-\mathrm{ZnGa}_{2} \mathrm{O}_{4}\right)$. So, the binding energy shifts $(\Delta \mathrm{BE} \sim 2.6 \mathrm{eV})$ of the valence band $\mathrm{Zn} 3 d$ peaks (when comparing $n$-type and $p$-type $\mathrm{ZnGa}_{2} \mathrm{O}_{4}$ ) is much more pronounced than the one from the core levels. Again, there is a strong reminiscence of the $n$ - $\mathrm{ZnO}$ valence band shape and $n-\mathrm{ZnGa}_{2} \mathrm{O}_{4}$ in terms of intensity and energy, except for a valley located at $8,6 \mathrm{eV}$ for $\mathrm{ZnO}$ (as if the $\mathrm{Zn} 3 d$ and $\mathrm{O} 2 p$ states were more separated for $\mathrm{ZnO}$ ). Analogously, $\mathrm{Ga} 3 d$ features present in $\mathrm{ZnGa}_{2} \mathrm{O}_{3}$ and $\mathrm{Ga}_{2} \mathrm{O}_{3}$ in the second valence band peaks at $20.3 \mathrm{eV}$ for $n-\mathrm{ZnGa}_{2} \mathrm{O}_{4}$ and $\mathrm{Ga}_{2} \mathrm{O}_{3}$ (either $n$ or $p$ ) while peaks at $17.7 \mathrm{eV}$ for $p$ $\mathrm{ZnGa}_{2} \mathrm{O}_{4}(\triangle \mathrm{BE} \sim 2.6 \mathrm{eV})$. Therefore, in practice, the Fermi level (as determined from the top band slope) is shifted $\sim 2.8 \mathrm{eV}$ from $p-\mathrm{ZnGa}_{2} \mathrm{O}_{4}\left(E_{F} \sim 0.5 \mathrm{eV}\right)$, up to $E_{F} \sim 3.3 \mathrm{eV}$ for $n-\mathrm{ZnGa}_{2} \mathrm{O}_{4}$. This result already agrees well with the fact that the Fermi energy is in the upper part of the bandgap for $n-\mathrm{ZnGa}_{2} \mathrm{O}_{4}$ and in the lower half of the bandgap for $p-\mathrm{ZnGa}_{2} \mathrm{O}_{4}$. However, considering an electronic bandgap of $\sim 5 \mathrm{eV}$ for $n-\mathrm{ZnGa}_{2} \mathrm{O}_{4}$, the Fermi level is still around $\sim 1.9 \mathrm{eV}$ from the conduction band edge $\left(\mathrm{E}_{\mathrm{c}}\right)$. Thus, this would not explain the high concentration of free carriers at room temperature for $n-\mathrm{ZnGa}_{2} \mathrm{O}_{4}$. A plausible explanation for the room temperature conductivity of $n-\mathrm{ZnGa}_{2} \mathrm{O}_{4}$ is the formation of an impurity conductive band [57] as revealed by optical spectroscopy.

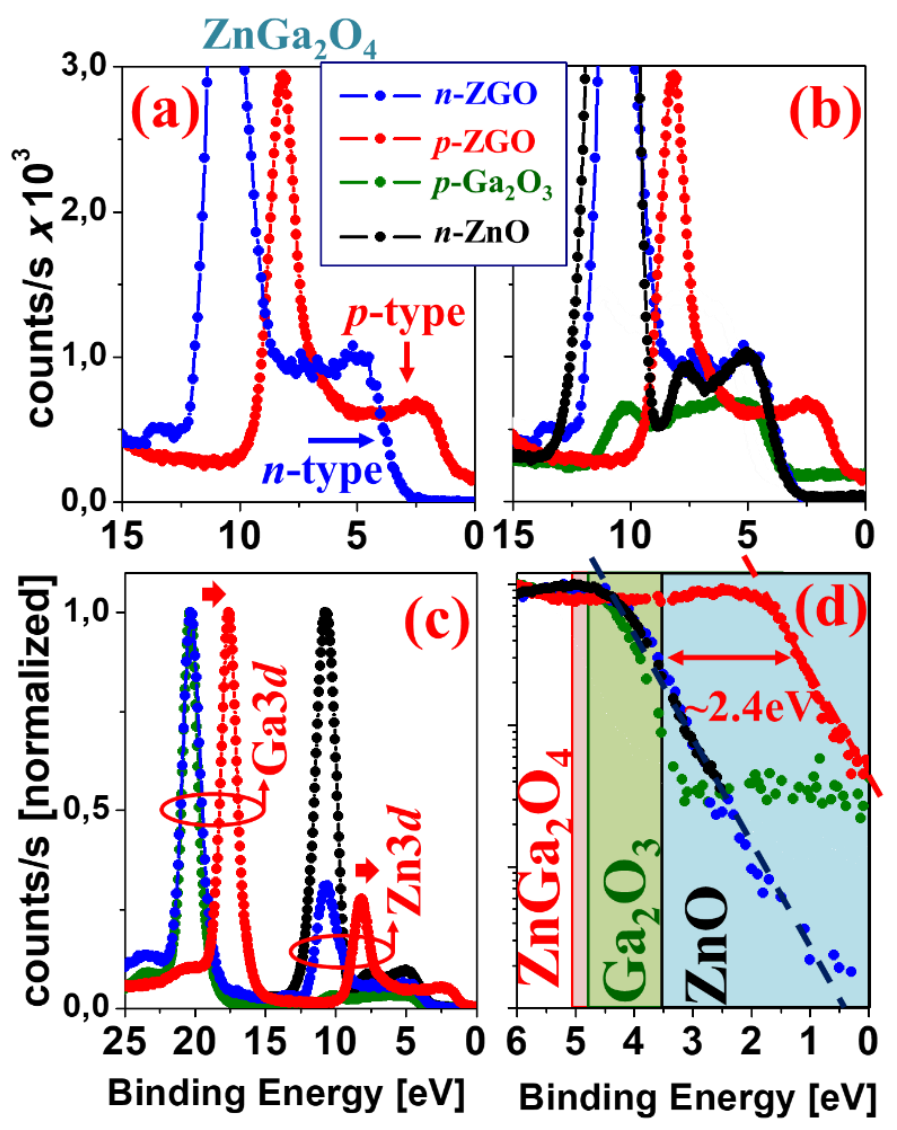


Fig.3. (a) Experimental XPS high-resolution valence band for the $n$-type $\mathrm{ZnGa}_{2} \mathrm{O}_{4}$ (ZGO) and $p$-type $\mathrm{ZnGa}_{2} \mathrm{O}_{4}$ as a reference. (b) Experimental XPS high-resolution of the first valence band group for $n$-type $\mathrm{ZnGa}_{2} \mathrm{O}_{4}$, $p$-type $\mathrm{ZnGa}_{2} \mathrm{O}_{4}$, pure $\mathrm{ZnO}$ and pure $p$-type $\beta-\mathrm{Ga}_{2} \mathrm{O}_{3}$ for comparison. (c) Idem, for the first and the second group of valence bands. (d) A zoom of the valence band region (VBM) showing the presence of tail states in the lower part of the bandgap for the $p$-type compounds (the value of the bandgap is depicted for $\mathrm{ZnO}, \beta-\mathrm{Ga}_{2} \mathrm{O}_{3}$ and $\mathrm{ZnGa}_{2} \mathrm{O}_{4}$ ).

Optical transmittance and optical bandgap determination by Tauc's plot for $n-\mathrm{ZnGa}_{2} \mathrm{O}_{4}$ and $p-\mathrm{ZnGa}_{2} \mathrm{O}_{4}$ samples are shown in FIG.4. Both $n$-type and $p$-type thin layers exhibit high transparency $>80 \%$ in 360 to $1000 \mathrm{~nm}$ wavelength range, the values of optical bandgaps determined from absorption edges in UV region are $4.9 \mathrm{eV}$ and $4.8 \mathrm{eV}$, respectively (FIG.4-b). Contrary to the sharp edge of $p$ - $\mathrm{ZnGa}_{2} \mathrm{O}_{4}$, for the $n-\mathrm{ZnGa}_{2} \mathrm{O}_{4}$ sample, there is another absorption band at around $360 \mathrm{~nm}$ (FIG.4-a). Such an absorption band has been already reported in conducting thin films [39] without clear identification of the origin. Interestingly, other groups have observed PL emissions peaking at $340 \mathrm{~nm}$ in zinc gallate and this emission has been associated with $\mathrm{Ga}^{3+}$ ions substitution into the $\mathrm{Zn}^{2+}$ ions site [40,58]. Our results suggest however that, rather than $\mathrm{Ga}_{\mathrm{Zn}}$ antisites, this absorption at $360 \mathrm{~nm}(\sim 3.4 \mathrm{eV})$ might be associated with $\mathrm{Zn}$ atoms having strong bond with oxygen, leading to $\mathrm{Zn}-\mathrm{O}$ hybridization. The position of this band agrees with the findings from XPS analysis (location of Fermi level). At high doping levels, the neighboring impurities have overlapping wave functions causing the single donor level to split and turn into a band, known as an impurity band. The states in the impurity band are localized, resulting in electron transport that is dominated by tunneling and hopping [57] as we will demonstrate in the following section.
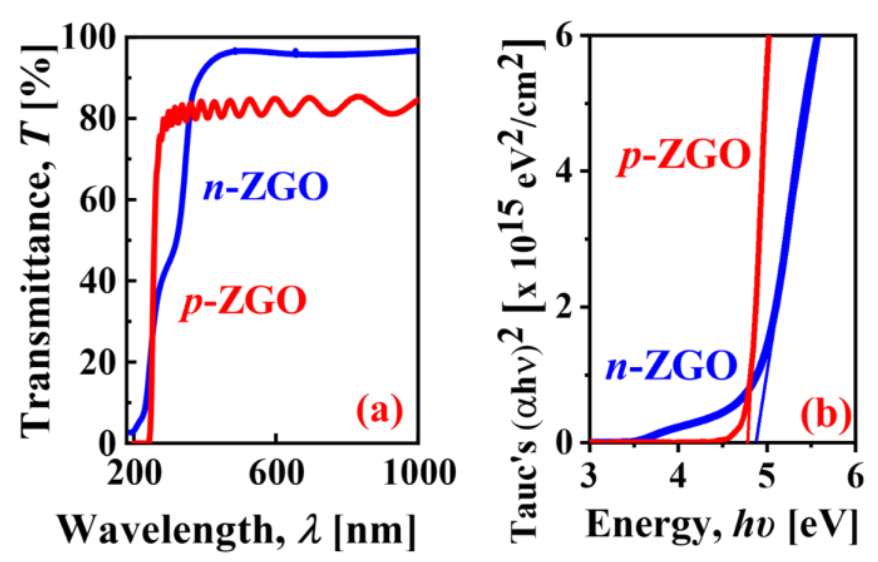

Fig.4. (a) Room temperature optical transmittance spectra and (b) direct bandgap determination by Tauc's plot for both $n$-type and $p$-type $\mathrm{ZnGa}_{2} \mathrm{O}_{4}$ thin films.

\section{Electrical Transport of $n$-type and $p$-type $\mathrm{ZnGa}_{2} \mathrm{O}_{4}$ thin films}

Electrical transport measurement of undoped $p$-type $\mathrm{ZnGa}_{2} \mathrm{O}_{4}$ thin film was carried out in a Van der Pauw configuration, and is presented in FIG.5-c and -d. As the layer's resistance below $500 \mathrm{~K}$ exceeded the measurement limit of our set-up $\left(\sim 5 \times 10^{10} \Omega\right)$, the measurement was performed only at high temperature $(500-850 \mathrm{~K})$. The mobilities of the $p-\mathrm{ZnGa}_{2} \mathrm{O}_{4}$ thin film was measured between 7 and $10 \mathrm{~cm}^{2} \mathrm{~V}^{-1} \mathrm{~s}^{-1}$ in this temperature range. The pure $p-\mathrm{ZnGa}_{2} \mathrm{O}_{4}$ thin film is highly resistive: $\rho_{p \text {-ZGO }}=1.3 \times 10^{3} \Omega$.cm with a hole 
concentration of $p=1.6 \times 10^{15} \mathrm{~cm}^{-3}$ at $850 \mathrm{~K}$. This $p$-type conductivity was explained by the fact of self dopability, ie. presence of acceptor antisite $\left(\mathrm{Zn}_{\mathrm{Ga}}\right)$ defects [43]. Though, conductivity is quite low, indicating that those samples are of low inversion degree, still not very far from stoichiometric composition. Further work is required to find growth condition with enhancing possibility of acceptor $\mathrm{Zn}_{\mathrm{Ga}}$ defects formation, leading to higher hole conductivity.

Very differently, for $n$-type $\mathrm{ZnGa}_{2} \mathrm{O}_{4} 190 \mathrm{~nm}$ film at room temperature, Van Der Pauw configuration resistivity was found to be exceptionally low: $\rho_{n-\mathrm{ZGO}}=3.2 \times 10^{-2} \Omega . \mathrm{cm}$. Hall effect measurement at $300 \mathrm{~K}$ with magnetic field of $1.6 \mathrm{~T}$ reveals an electron concentration of $n=3.7 \times 10^{19} \mathrm{~cm}^{-3}$, and a mobility of $\mu=$ $5.3 \mathrm{~cm}^{2} \mathrm{~V}^{-1} \mathrm{~s}^{-1}$. Additionally, the Seebeck Effect has confirmed $n$-type conductivity of the thin layer, with a coefficient of $S_{300 \mathrm{~K}}=-30.2 \mu \mathrm{V} / \mathrm{K}$. Oxygen vacancies are traditionally considered the source of electrons in semiconductor oxides and for $\mathrm{ZnGa}_{2} \mathrm{O}_{4}$ spinel the same explanation has already been proposed in several works [35-37,41]. However, oxygen vacancy as a native Frenkel type defect is supposed to be a deep level defects in ultra-wide bandgap $\mathrm{ZnGa}_{2} \mathrm{O}_{4}$ [21,28,42], thus it cannot be the origin of high electron concentrations at room temperature.

To elucidate the mechanism of conductivity, the temperature dependence electrical transport measurements of the $n$-type $\mathrm{ZnGa}_{2} \mathrm{O}_{4}$ has been carried out in four-point aligned configuration by physical property measurement system (PPMS), FIG.5-a, 5-b. The resistivity values are $2.7-6.9 \times 10^{-2} \Omega . c m$ for 2 $300 \mathrm{~K}$. The resistivity is almost invariant in the $100-300 \mathrm{~K}$ temperature range, while exhibiting a tendency to increase when $\mathrm{T}<100 \mathrm{~K}$. To the best of our knowledge, such highly conducting thin films have only been reported by D. Look et al. [39], $\rho=4.2 \times 10^{-2} \Omega$.cm for a PLD deposited sample, and $\rho=5.6 \times 10^{-3} \Omega . \mathrm{cm}$ for a MOCVD grown sample [16,17].
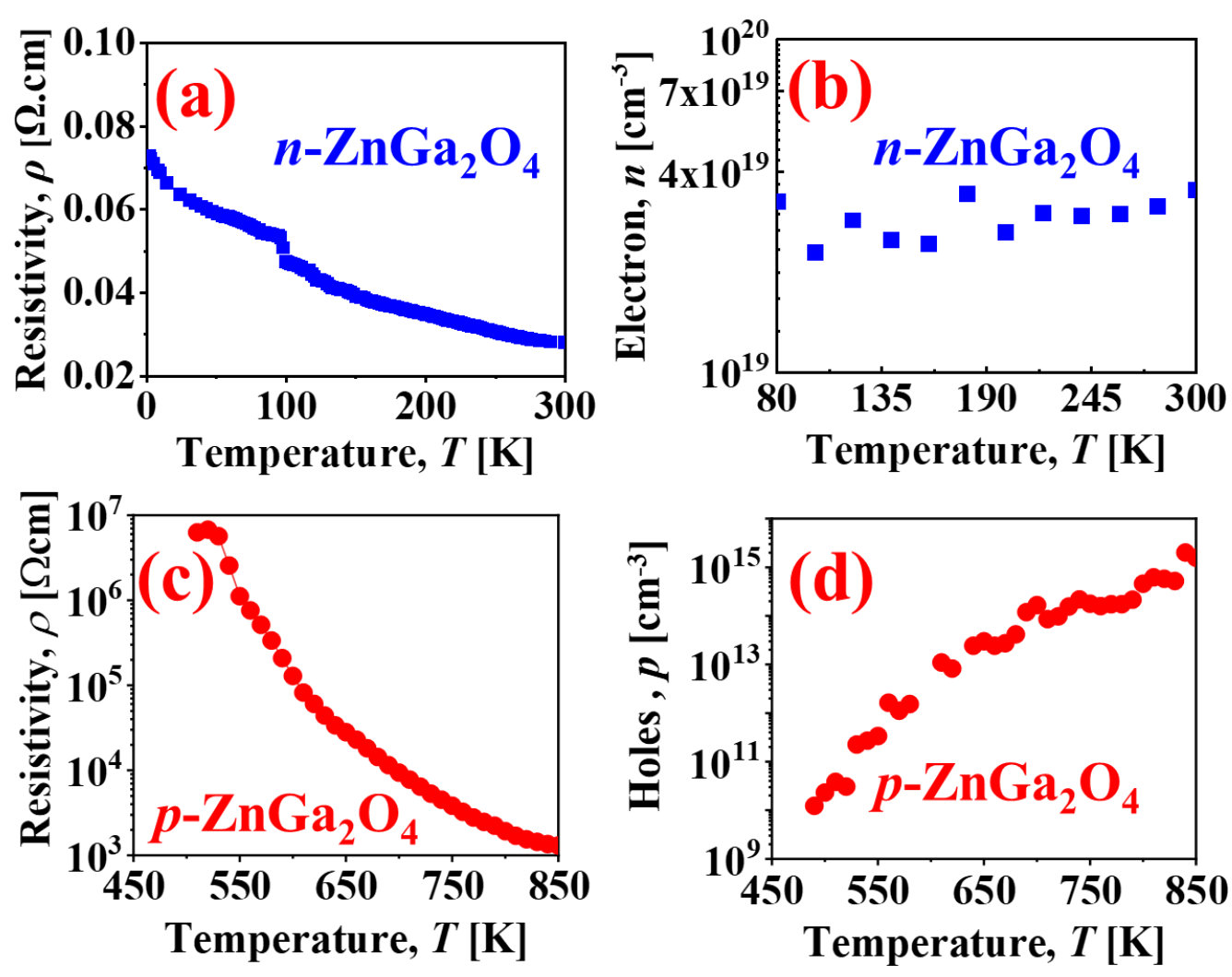
Fig.5. $n-\mathrm{ZnGa}_{2} \mathrm{O}_{4}$ thin film (a) electrical resistivity versus temperature dependence from aligned four-probe measurements; (b) electron concentration from Hall effect measurements in Van der Pauw configuration. Pure $p$-type $\mathrm{ZnGa}_{2} \mathrm{O}_{4}$ layer (c) electrical resistivity and (d) hole concentration versus temperature determined from Hall effect measurement.

Observing such a high electrical conductivity in ultra-wide bandgap material, one can think about surface conduction caused by the charge accumulation [59,60]. Though we are discarding this hypothesis since it is not observed any signature of surface 2D conductivity (decrease resistivity with temperature and hockey-stick shape of $\rho(T)$ [61-65]. Thus, the only probable explanation for such high electrical conduction can be the so-called self-doping effect in spinels.

By means of the comparison of XRD, TEM, electrical transport properties, local bonding environment of $\mathrm{Zn}, \mathrm{Ga}, \mathrm{O}$, and optical transmittance of $n$-type $\mathrm{ZnGa}_{2} \mathrm{O}_{4}$ and $p$-type $\mathrm{ZnGa}_{2} \mathrm{O}_{4}$ thin films, the most remarkable differences come from the binding energy of $\mathrm{O} 1 \mathrm{~s}$ and valence band tail, which have a great similarity of $\mathrm{ZnO}$, while the material is structurally $\mathrm{ZnGa}_{2} \mathrm{O}_{4}$. Indeed, the defect-defect interaction has already been considered of natively $n$-type conductivity $\mathrm{ZnO}$. This interaction is driven by the quantum mechanical hybridization between two donor-like defects, the deep donor oxygen vacancy $\mathrm{V}_{O}$ and the shallow donor zinc interstitial $\mathrm{Zn}_{\mathrm{i}}$. This interaction happens in our $\mathrm{Zn}$-rich and O-deficient zinc gallate, and significantly reduces the total energy of the system, leads to a high electron concentration of $\mathrm{Zn}_{\mathrm{i}}$ [66], even though they are not as energetically favorable as antisite defects $\mathrm{Zn}_{\mathrm{Ga}}$ and $\mathrm{Ga} \mathrm{Zn}$ in stoichiometric $\mathrm{ZnGa}_{2} \mathrm{O}_{4}$ $[21,67]$. An energy level is thus introduced by these defects but within the gap, $3.2 \mathrm{eV}$ from the valance band. In practice, it means that this donor level is relatively deep (bandgap $\mathrm{Eg}=4.9 \mathrm{eV}$ ) and cannot be activated at room temperature -being the source of free carriers. Consequently, it supposes that observed room temperature electrical conductivity might be rather due to localized carriers, as it happens for impurity conduction for highly doped semiconductors.

We have analyzed the electrical transport properties considering this hypothesis. Localization of free carriers leads to different hopping mechanism depending on temperature regions. Indeed, 2 slopes could be distinguished by $\log (\sigma)$ versus $1 / T$ plot $(\sigma=1 / \rho)$. As shown by Fig.6-a, the first "high temperature" interval corresponds to nearest-neighbor hopping $(\mathrm{NNH})$ conduction. The conductivity in the nearest-neighbor hopping regime can be simply described by the expression $\sigma(T)=\sigma_{0} T^{-1} \exp \left(-\varepsilon / K_{B} T\right)$ [68], where $\sigma_{0}$ being a function of the impurity concentration is independent of the temperature $\mathrm{T}, \mathrm{k}_{\mathrm{B}}$ is the Boltzmann constant, $\varepsilon$ is an activation energy for hops from one site to the nearest one in the impurity band, it is temperature independent and was estimated as $E_{a}=20.9 \mathrm{meV}$ (Fig.6-a). With lower temperatures (<100 K), electrons do not have enough energy to hop at the nearest-neighbor sites. Thus, the variable range hopping (VRH) takes place and as it is shown in Fig.6-b, the conductivity in this temperature interval can be well fitted with $T^{1 / 4}$ dependence, corresponding to Mott's VRH mechanism.

As we demonstrate, in undoped non-stoichiometric $n$-type $\mathrm{ZnGa}_{2} \mathrm{O}_{4}$ the self-doping effect is due to hybridization between zinc and oxygen orbitals. Such a rich number of point defects usually lead a system 
disorder where the periodic potential in the crystal structure is destroyed. Therefore, such a disorder could lead to carrier localization which is the so-called Anderson's localization [69,70]. The high level of the disorder can induce metal-insulator transition (MIT) non-interacting electrons in three dimensions (3D) at zero magnetic field and in the absence of spin-orbit coupling [71]. However, for our $n$-type zinc gallate sample, there is no strong change of resistivity indicating the metal-insulator transition (MIT) (Fig.6-a). It emerges that the disorder due to the self-doping effect is not strong enough, indicating the relatively low deviation from stoichiometry.

To further understand the conduction mechanism, the magnetoresistance (MR, in \%) was measured with a magnetic field applied perpendicular to the film plane (i.e. the current). The resistances as a function of the magnetic field for $n$-type $\mathrm{ZnGa}_{2} \mathrm{O}_{4}$ thin film at different temperature are shown by Fig.6-c. The MR decreases with the increasing field (absolute value), and is negative from $2 \mathrm{~K}$ up to $100 \mathrm{~K}$, then vanishes at $\mathrm{T}>100 \mathrm{~K}$. Such negative magnetoresistance is usually observed for nonmagnetic semiconductors when heavily doped [72]. In the present case, in the undoped $n-\mathrm{ZnGa}_{2} \mathrm{O}_{4}$ high concentration of carriers is related to native defects. We could think that there is a conducting channel similar to the "impurity band" in external impurity doped semiconductors. Such a "self-impurity" band we attribute to the Zn related donor defect.

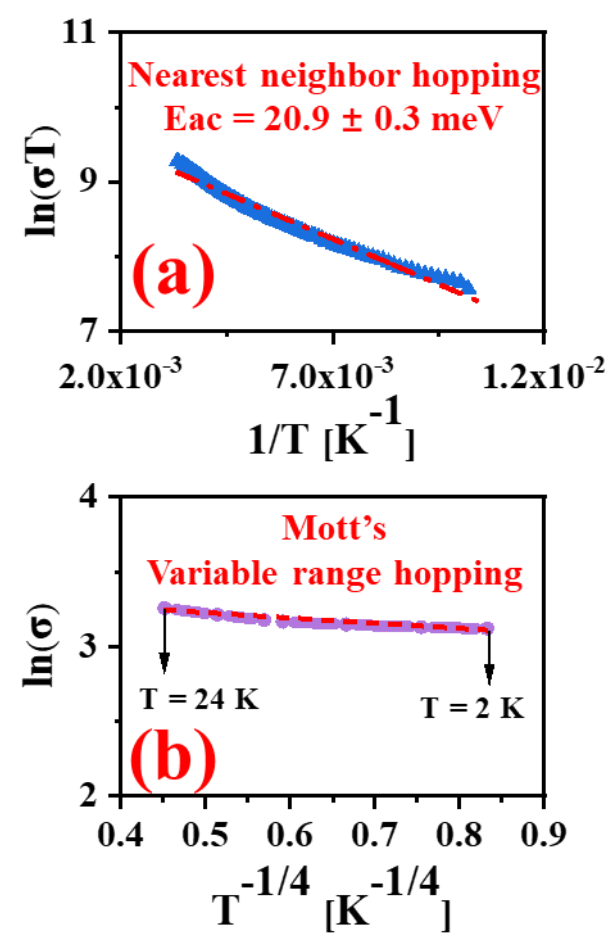

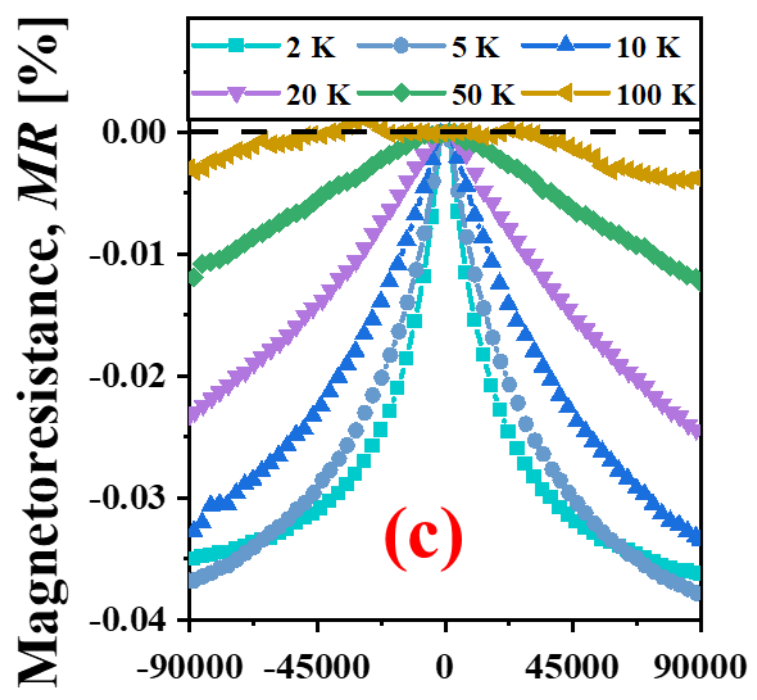

Applied magnetic field, $\mu_{0} H[\mathrm{Oe}]$

Fig.6. $n$-type $\mathrm{ZnGa}_{2} \mathrm{O}_{4}$ (a) $\log (\sigma \mathrm{T})$ versus $1 / \mathrm{T}$ in the nearest-neighbor hopping regime; (b) $\ln (\sigma)$ versus $\mathrm{T}^{-1 / 4}$ showing the variable range hopping regime (VRH); (c) Resistance versus magnetic field at different temperatures $(2-100 \mathrm{~K})$ in perpendicular to current magnetic field orientation. Measurements were done in four-probe aligned configuration. 


\section{Conclusion}

At the time being, spinel $\mathrm{ZnGa}_{2} \mathrm{O}_{4}$ arguably is the bipolar ternary oxide semiconductor with the largest bandgap $(\sim 5 \mathrm{eV})$. Besides, $\mathrm{ZnGa}_{2} \mathrm{O}_{4}$ thin films can be grown perfectly epitaxial directly on cheap sapphire substrates, which makes this material interesting from a practical perspective.

$p$-type and $n$-type $\mathrm{ZnGa}_{2} \mathrm{O}_{4}$ epilayers can be grown by tuning the total pressure, oxygen flow and cation precursors ratio during metal-organic chemical vapor deposition. State-of-the-art analytical techniques provide no evidence of contamination or secondary phases. These experimental facts raise-up the immediate question of which the origin of the conductivity is and challenge our general view of $\mathrm{ZnGa}_{2} \mathrm{O}_{4}$ being a typical insulator representative. Here, based on complementary structural, chemical, optical and electrical transport measurements, we conclude that the origin of high room temperature $n$-type conductivity $\left(\sim 3.2 \times 10^{-}\right.$

${ }^{2} \Omega . \mathrm{cm}$ at room temperature) is related to the "self-impurity" band located Ev+ $\sim 3.4 \mathrm{eV}$ from the valence band edge. This band is a consequence of $\mathrm{Zn}-\mathrm{O}$ orbital's hybridization in $\mathrm{Zn}$-rich and O-deficient $\mathrm{ZnGa}_{2} \mathrm{O}_{4}$ material. Otherhand, hole conductivity in $p-\mathrm{ZnGa}_{2} \mathrm{O}_{4}$ is achieved thanks to $\mathrm{Zn}_{\mathrm{Ga}}$ antisite defects.

We believe that our work is the further evidence of outstanding prospects of $\mathrm{ZnGa}_{2} \mathrm{O}_{4}$ material for extending the frontiers of solid-state energy optoelectronics. 


\section{Experimental details}

\section{A. Growth of the $\mathrm{ZnGa}_{2} \mathrm{O}_{4}$ thin film}

p-type $\mathrm{ZnGa}_{2} \mathrm{O}_{4}$ sample was grown in a MOCVD reactor on c-oriented sapphire $\left(\mathrm{Al}_{2} \mathrm{O}_{3}\right)$ substrates. The TMGa and DEZn bubbler temperatures were fixed at $-10^{\circ} \mathrm{C}$ and $0^{\circ} \mathrm{C}$. During the growth, the flow rates of the $\mathrm{Ga}, \mathrm{Zn}$ and $\mathrm{O}$ precursors trimethylgallium (TMGa), diethylzinc (DEZn) and oxygen were kept at 11 $\mu \mathrm{mol} / \mathrm{min}, 8.9 \mu \mathrm{mol} / \mathrm{min}$ and $1200 \mathrm{sccm}$, respectively. The growth temperature, pressure, and time were set at $775{ }^{\circ} \mathrm{C}, 38$ Torr, and $150 \mathrm{~min}$, respectively. The thickness was determined as $\sim 1 \mu \mathrm{m}$ by cross-sectional scanning electron microscope (SEM) and transmission electron microscopy (TEM). The $n$-type ZGO epitaxial film with $190 \mathrm{~nm}$ thickness was grown on c- oriented sapphire $\left(\mathrm{Al}_{2} \mathrm{O}_{3}\right)$ substrates at $850{ }^{\circ} \mathrm{C}$ by MOCVD, which Diethylzinc (DEZn), Triethylgallium (TEGa), and oxygen were used for $\mathrm{Zn}, \mathrm{Ga}$, and O precursors, and the flow rate of precursors were maintained at 49, $27 \mu \mathrm{mol} / \mathrm{min}$ and $0.022 \mathrm{~mol} / \mathrm{min}$, respectively. The substrate temperature, growth pressure, and growth time were $850{ }^{\circ} \mathrm{C}, 25$ torr, and 30 minutes, respectively. After finishing the film deposition, the epilayer was annealed at $850^{\circ} \mathrm{C}$ in nitrogen ambient for 1 hour to improve the ZGO crystallization.

\section{B. Materials characterization}

B.1. XRD: The X-ray diffraction was used to investigate the crystalline structure of $\mathrm{ZnGa}_{2} \mathrm{O}_{4}$ film by Siemens D5000 X-ray diffractometer with $\mathrm{Cu}-\mathrm{K} \alpha 1$ source of $\lambda=0,1541 \mathrm{~nm}$, and recorded between 15 and $65^{\circ}$ for both $n-\mathrm{ZnGa}_{2} \mathrm{O}_{4}$ and $p-\mathrm{ZnGa}_{2} \mathrm{O}_{4}$ thin films.

B.2. GDOES: The elemental depth profile $n-\mathrm{ZnGa}_{2} \mathrm{O}_{4}$ film was obtained on a GD Profiler 2 instrument (Horiba) using a Pulsed Radio Frequency source. The obtained light intensity signals of the elements are displayed in arbitrary units.

B.3. TEM (HR TEM, SAED): The microstructure of $n-\mathrm{ZnGa}_{2} \mathrm{O}_{4}$ film was investigated by highresolution transmission electron microscopy (HR TEM, JEOL-2100F CS STEM) equipped a 200-kV field emission electron gun (FEG) and combined with selected area electron diffraction (SAED). The TEM sample was prepared using focus ion beam (FIB, Hitachi NX2000). A protective and conductive Pt layer was first deposited before milling the cross-sectional lamella with a Ga ion source. For high resolution TEM observation, the final thinning process was performed by reducing the voltage and current to $5 \mathrm{kV}$ and $40 \mathrm{pA}$, respectively. For $p$ - $\mathrm{ZnGa2O}$, this characterization and imaging were conducted using a field emission gun FEI Tecnai F20 microscope at $200 \mathrm{kV}$ with a point-to-point resolution of $0.24 \mathrm{~nm}$. Energy dispersive X-ray (EDX) and electron energy loss spectroscopy (EELS) spectrum images and profiles were obtained in high angle annular dark-field (HAADF) STEM mode with an EDAX super ultra-thin window (SUTW) X-ray detector a Gatan Quantum SE 963 imaging filter respectively. TEM cross-sections were prepared by conventional mechanical polishing and ion milling.

B.4. XPS: Regular XPS analyses for $n$-type $\mathrm{ZnGa}_{2} \mathrm{O}_{4}$ thin film, was performed at ILV, were conducted on a Thermofisher Scientific Escalab 250 xi equipped with a monochromated Al-Ka anode (1486.6 eV) and 
a dual flood gun (low energy electron and ion). High energy resolution spectral windows of interest were recorded with a $650 \mu \mathrm{m}$ spot size. The photoelectron detection was performed using a constant analyzer energy (CAE) mode ( $20 \mathrm{eV}$ pass energy) and a $0.1 \mathrm{eV}$ energy step. All the associated binding energies were corrected with respect to C-C component of adventitious carbon at $284.8 \mathrm{eV}$. Quantification was performed based on the $\mathrm{O} 1 s, \mathrm{C} 1 s, \mathrm{Ga} 2 p_{3 / 2}$ and $\mathrm{Zn} 2 p_{3 / 2}$ photopeak areas after a Shirley type background subtraction using the Thermofisher Scientific Avantage(C software and its "ALTHERMO1" library as sensitivity factor collection. For $p-\mathrm{ZnGa} 2 \mathrm{O} 4$, the measurements were performed with a Phoibos 150 analyzer (SPECS GmbH, Berlin, Germany) in ultra-high vacuum conditions (base pressure $3 \times 10^{-10} \mathrm{mbar}$ ). XPS measurements were performed with a monochromatic $\mathrm{Al} \mathrm{Ka}$ X-ray source (1486.74 eV). The main $\mathrm{ZnGa}_{2} \mathrm{O}_{4} \mathrm{Ga} 2 p$ and $\mathrm{Zn} 2 p$ peak energies were consistent with previous literature after adventitious $\mathrm{C} 1 \mathrm{~s}$ calibration $(284.8 \mathrm{eV})$. The $\mathrm{C} 1 \mathrm{~s}$ calibration shift for the reference $\mathrm{ZnGa}_{2} \mathrm{O}_{4}$ was only of $0,595 \mathrm{eV}$. The $\mathrm{C} 1 \mathrm{~s}$ calibration shift energies were also relatively small for the other specimens with $-0.3 \mathrm{eV}$ and 2,8 for reference ( $n$-type) $\mathrm{ZnO}$ and (highly resistive) $\mathrm{Ga}_{2} \mathrm{O}_{3}$, respectively.

B.5. Optical transmittance: Optical transmittance spectrum of $n-\mathrm{ZnGa}_{2} \mathrm{O}_{4}$ thin film was measured by $\mathrm{n} \& \mathrm{k}$ system. Whereas the $p-\mathrm{ZnGa}_{2} \mathrm{O}_{4}$ thin film was measured in $200-2000 \mathrm{~nm}$ spectral range with a Perklin Elmer 9 spectrophotometer.

B.6. Hall effect: Hall effect measurements were performed in a Van der Pauw configuration by custom designed high impedance measurement set-up with magnetic fields of $0-1.6 \mathrm{~T}$ perpendicular to the film plane. The measurement temperature range was $80-300 \mathrm{~K}$ in case of $n-\mathrm{ZnGa}_{2} \mathrm{O}_{4}$ sample, while $p-\mathrm{ZnGa}_{2} \mathrm{O}_{4}$ sample was measured in 500 - $850 \mathrm{~K}$ temperature interval.

B.7. Seebeck effect: Carrier type testing was done by using Seebeck effect measurements at $300-400 \mathrm{~K}$ with a home-built set-up (also specially adapted for high impedance samples) based on a Keithley SCS-4200 measurement station and cascade Microtech Kelvin probes.

B.8. DC-resistivity and magnetoresistance: The $n$-type $\mathrm{ZnGa}_{2} \mathrm{O}_{4}$ samples were studied by the standard "resistivity" option of 9T physical property measurement system (PPMS, Quantum Design) equipment, using the four-point aligned configuration.

\section{Acknowledgements}

This study was financially supported by Ministry of Science and Technology, Taiwan (MOST 1092622-E-009-033， 108-2618-E-009-031，109-2224-E-009-002，109-2634-F-009-028， 109-2221-E-009-143MY3, 108-2628-E-002-010-MY3) and the Higher Education SPROUT Project-Center for Emergent Functional Matter Science of National Yang Ming Chiao Tung University. 


\section{Reference}

[1] S.J. Pearton, J. Yang, P.H. Cary, F. Ren, J. Kim, M.J. Tadjer, M.A. Mastro, A review of Ga2O3 materials, processing, and devices, Appl. Phys. Rev. 5 (2018) 011301. https://doi.org/10.1063/1.5006941.

[2] J.Y. Tsao, S. Chowdhury, M.A. Hollis, D. Jena, N.M. Johnson, K.A. Jones, R.J. Kaplar, S. Rajan, C.G.V. de Walle, E. Bellotti, C.L. Chua, R. Collazo, M.E. Coltrin, J.A. Cooper, K.R. Evans, S. Graham, T.A. Grotjohn, E.R. Heller, M. Higashiwaki, M.S. Islam, P.W. Juodawlkis, M.A. Khan, A.D. Koehler, J.H. Leach, U.K. Mishra, R.J. Nemanich, R.C.N. Pilawa-Podgurski, J.B. Shealy, Z. Sitar, M.J. Tadjer, A.F. Witulski, M. Wraback, J.A. Simmons, Ultrawide-Bandgap Semiconductors: Research Opportunities and Challenges, Adv. Electron. Mater. 4 (2018) 1600501. https://doi.org/10.1002/aelm.201600501.

[3] E. Chikoidze, T. Tchelidze, C. Sartel, Z. Chi, R. Kabouche, I. Madaci, C. Rubio, H. Mohamed, V. Sallet, F. Medjdoub, A. Perez-Tomas, Y. Dumont, Ultra-high critical electric field of $13.2 \mathrm{MV} / \mathrm{cm}$ for Zn-doped p-type $\quad \beta-\mathrm{Ga}_{2} \mathrm{O}_{3}$, Mater. $\quad$ Today $\quad$ Phys. $15 \quad$ (2020) 100263. https://doi.org/10.1016/j.mtphys.2020.100263.

[4] M.N. da Silva, J.M. de Carvalho, M.C. de Abreu Fantini, L.A. Chiavacci, C. Bourgaux, Nanosized ZnGa2O4:Cr3+ Spinels as Highly Luminescent Materials for Bioimaging, ACS Appl. Nano Mater. 2 (2019) 6918-6927. https://doi.org/10.1021/acsanm.9b01417.

[5] H. Peelaers, J.B. Varley, J.S. Speck, C.G. Van de Walle, Structural and electronic properties of Ga2O3-A12O3 alloys, Appl. Phys. Lett. 112 (2018) 242101. https://doi.org/10.1063/1.5036991.

[6] J. Zhao, X.W. Sun, S.T. Tan, Bandgap-Engineered Ga-Rich GaZnO Thin Films for UV Transparent Electronics, IEEE Trans. Electron Devices. $56 \quad$ (2009) 2995-2999. https://doi.org/10.1109/TED.2009.2033010.

[7] A.F.M.A.U. Bhuiyan, Z. Feng, J.M. Johnson, H.-L. Huang, J. Sarker, M. Zhu, M.R. Karim, B. Mazumder, J. Hwang, H. Zhao, Phase transformation in MOCVD growth of $\left(\mathrm{Al}_{x} \mathrm{Ga}_{1-\mathrm{x}}\right)_{2} \mathrm{O}_{3}$ thin films, APL Mater. 8 (2020) 031104. https://doi.org/10.1063/1.5140345.

[8] J. Boy, M. Handwerg, R. Mitdank, Z. Galazka, S.F. Fischer, Charge carrier density, mobility, and Seebeck coefficient of melt-grown bulk $\mathrm{ZnGa}_{2} \mathrm{O}_{4}$ single crystals, AIP Adv. 10 (2020) 055005. https://doi.org/10.1063/5.0002847.

[9] S.-H. Tsai, Y.-C. Shen, C.-Y. Huang, R.-H. Horng, Deep-ultraviolet Schottky photodetectors with high deep-ultraviolet/visible rejection based on a $\mathrm{ZnGa}_{2} \mathrm{O}_{4}$ thin film, Appl. Surf. Sci. 496 (2019) 143670. https://doi.org/10.1016/j.apsusc.2019.143670.

[10] A. Luchechko, Y. Zhydachevskyy, S. Ubizskii, O. Kravets, A.I. Popov, U. Rogulis, E. Elsts, E. Bulur, A. Suchocki, Afterglow, TL and OSL properties of Mn 2+-doped ZnGa 2 O 4 phosphor, Sci. Rep. 9 (2019) 9544. https://doi.org/10.1038/s41598-019-45869-7.

[11] T. Maldiney, A. Bessière, J. Seguin, E. Teston, S.K. Sharma, B. Viana, A.J.J. Bos, P. Dorenbos, M. Bessodes, D. Gourier, D. Scherman, C. Richard, The in vivo activation of persistent nanophosphors 
for optical imaging of vascularization, tumours and grafted cells, Nat. Mater. 13 (2014) 418-426. https://doi.org/10.1038/nmat3908.

[12] P.-H. Huang, Y.-C. Shen, C.-Y. Tung, C.-Y. Huang, C.S. Tan, R.-H. Horng, Energy-Saving ZnGa ${ }_{2} \mathrm{O}$ ${ }_{4}$ Phototransistor Improved by Thermal Annealing, ACS Appl. Electron. Mater. 2 (2020) 3515-3521. https://doi.org/10.1021/acsaelm.0c00394.

[13] Y.-C. Shen, P.-H. Huang, C.-Y. Tung, C.-Y. Huang, C.-S. Tan, Y.-S. Huang, L.-J. Chen, J.-H. He, R.H. Horng, Power Saving High Performance Deep-Ultraviolet Phototransistors Made of ZnGa2O4 Epilayers, ACS Appl. Electron. Mater. 2 (2020) 590-596. https://doi.org/10.1021/acsaelm.9b00820.

[14] Y.C. Shen, C.Y. Tung, C.Y. Huang, Y.C. Lin, Y.G. Lin, R.H. Horng, Study on optoelectronic characteristic of ZnGa2O4 thin-film phototransistors, ACS Appl. Electron. Mater. 1 (2019) 783.

[15] J.-C. Tung, Y.-H. Chiang, D.-Y. Wang, P.-L. Liu, Adsorption of NO2 and H2S on ZnGa2O4(111) Thin Films: A First-Principles Density Functional Theory Study, Appl. Sci. 10 (2020) 8822. https://doi.org/10.3390/app10248822.

[16] L.C. Cheng, C.Y. Huang, R.H. Horng, Thickness effect on operational modes of ZnGa2O4 MOSFETs, IEEE J Electron Devices Soc. 6 (2018) 432.

[17] Y.-S. Shen, W.-K. Wang, R.-H. Horng, Characterizations of Metal-Oxide-Semiconductor Field-Effect Transistors of ZnGaO Grown on Sapphire Substrate, IEEE J. Electron Devices Soc. 5 (2017) 112-116. https://doi.org/10.1109/JEDS.2017.2653419.

[18] D. Guo, Q. Guo, Z. Chen, Z. Wu, P. Li, W. Tang, Review of Ga2O3-based optoelectronic devices, Mater. Today Phys. 11 (2019) 100157. https://doi.org/10.1016/j.mtphys.2019.100157.

[19] A. Pérez-Tomás, E. Chikoidze, M.R. Jennings, S.A.O. Russell, F.H. Teherani, P. Bove, E.V. Sandana, D.J. Rogers, Wide and ultra-wide bandgap oxides: where paradigm-shift photovoltaics meets transparent power electronics, in: Oxide-Based Mater. Devices IX, International Society for Optics and Photonics, 2018: p. 105331Q. https://doi.org/10.1117/12.2302576.

[20] J. Zhang, J. Shi, D.-C. Qi, L. Chen, K.H.L. Zhang, Recent progress on the electronic structure, defect, and doping properties of $\mathrm{Ga}_{2} \mathrm{O}_{3}$, APL Mater. 8 (2020) 020906. https://doi.org/10.1063/1.5142999.

[21] T.R. Paudel, A. Zakutayev, S. Lany, M. d'Avezac, A. Zunger, Doping Rules and Doping Prototypes in A2BO4 Spinel Oxides, Adv. Funct. Mater. 21 (2011) 4493-4501. https://doi.org/10.1002/adfm.201101469.

[22] T. Dazai, S. Yasui, T. Taniyama, M. Itoh, Cation-Deficiency-Induced Crystal-Site Engineering for ZnGa2O4:Mn2+ Thin Film, Inorg. Chem. $59 \quad$ (2020) 8744-8748. https://doi.org/10.1021/acs.inorgchem.0c00359.

[23] X. Lu, W. Bian, Y. Li, H. Zhu, Z. Fu, Q. Zhang, Cation distributions and microwave dielectric properties of $\mathrm{Cu}$-substituted $\mathrm{ZnGa} 2 \mathrm{O} 4$ spinel ceramics, Ceram. Int. 43 (2017) 13839-13844. https://doi.org/10.1016/j.ceramint.2017.07.104.

[24] J. Li, Cation distribution dependence of magnetic properties of sol-gel prepared MnFe2O4 spinel ferrite nanoparticles, J. Magn. Magn. Mater. (2010) 5. 
[25] G. Srinivas Reddy, H. Sharma, P. Bhaskar, M. Manjunatha, Effect of type of fuel used and calcination temperature on the disorder-order transformation of zinc aluminate spinel during combustion synthesis, Mater. Chem. Phys. 253 (2020) 123388. https://doi.org/10.1016/j.matchemphys.2020.123388.

[26] T.R. Paudel, S. Lany, M. d'Avezac, A. Zunger, N.H. Perry, A.R. Nagaraja, T.O. Mason, J.S. Bettinger, Y. Shi, M.F. Toney, Asymmetric cation nonstoichiometry in spinels: Site occupancy in Co $2 \mathrm{ZnO} 4$ and Rh 2 ZnO 4, Phys. Rev. B. 84 (2011) 064109. https://doi.org/10.1103/PhysRevB.84.064109.

[27] A. Seko, F. Oba, I. Tanaka, Classification of spinel structures based on first-principles cluster expansion analysis, Phys. Rev. B. 81 (2010) 054114. https://doi.org/10.1103/PhysRevB.81.054114.

[28] Y. Shi, P.F. Ndione, L.Y. Lim, D. Sokaras, T.-C. Weng, A.R. Nagaraja, A.G. Karydas, J.D. Perkins, T.O. Mason, D.S. Ginley, A. Zunger, M.F. Toney, Self-Doping and Electrical Conductivity in Spinel Oxides: Experimental Validation of Doping Rules, Chem. Mater. 26 (2014) 1867-1873. https://doi.org/10.1021/cm404031k.

[29] M. Stoica, C. S Lo, P-type zinc oxide spinels: application to transparent conductors and spintronics, New J. Phys. 16 (2014) 055011. https://doi.org/10.1088/1367-2630/16/5/055011.

[30] J.D. Perkins, T.R. Paudel, A. Zakutayev, P.F. Ndione, P.A. Parilla, D.L. Young, S. Lany, D.S. Ginley, A. Zunger, N.H. Perry, Y. Tang, M. Grayson, T.O. Mason, J.S. Bettinger, Y. Shi, M.F. Toney, Inverse design approach to hole doping in ternary oxides: Enhancing p -type conductivity in cobalt oxide spinels, Phys. Rev. B. 84 (2011) 205207. https://doi.org/10.1103/PhysRevB.84.205207.

[31] A. Zakutayev, T.R. Paudel, P.F. Ndione, J.D. Perkins, S. Lany, A. Zunger, D.S. Ginley, Cation offstoichiometry leads to high $\mathrm{p}$-type conductivity and enhanced transparency in Co $2 \mathrm{ZnO} 4$ and Co 2 NiO 4 thin films, Phys. Rev. B. 85 (2012) 085204. https://doi.org/10.1103/PhysRevB.85.085204.

[32] S.B. Zhang, S.-H. Wei, Self-doping of cadmium stannate in the inverse spinel structure, Appl. Phys. Lett. 80 (2002) 1376-1378. https://doi.org/10.1063/1.1452789.

[33] M.-I. Chen, A.K. Singh, J.-L. Chiang, R.-H. Horng, D.-S. Wuu, Zinc Gallium Oxide-A Review from Synthesis to Applications, Nanomaterials. 10 (2020) 2208. https://doi.org/10.3390/nano10112208.

[34] R.-H. Horng, C.-Y. Huang, S.-L. Ou, T.-K. Juang, P.-L. Liu, Epitaxial Growth of $\mathrm{ZnGa}_{2} \mathrm{O}_{4}$ : A New, Deep Ultraviolet Semiconductor Candidate, Cryst. Growth Des. 17 (2017) 6071-6078. https://doi.org/10.1021/acs.cgd.7b01159.

[35] K.M. Krishna, M. Nisha, R. Reshmi, R. Manoj, A.S. Asha, M.K. Jayaraj, ELECTRICAL AND OPTICAL PROPERTIES OF ZnGa2O4 THIN FILMS DEPOSITED BY PULSED LASER DEPOSITION, Mater. FORUM. 29 (2005) 243-247.

[36] Z. Yan, H. Takei, H. Kawazoe, Electrical Conductivity in Transparent ZnGa2O4: Reduction and Surface-Layer Structure Transformation, J. Am. Ceram. Soc. 81 (2005) 180-186. https://doi.org/10.1111/j.1151-2916.1998.tb02311.x.

[37] T. Omata, N. Ueda, K. Ueda, H. Kawazoe, New ultraviolet-transport electroconductive oxide, $\mathrm{ZnGa}_{2}$ O 4 spinel, Appl. Phys. Lett. 64 (1994) 1077-1078. https://doi.org/10.1063/1.110937.

[38] Z. Galazka, S. Ganschow, R. Schewski, K. Irmscher, D. Klimm, A. Kwasniewski, M. Pietsch, A. Fiedler, I. Schulze-Jonack, M. Albrecht, T. Schröder, M. Bickermann, Ultra-wide bandgap, conductive, 
high mobility, and high quality melt-grown bulk $\mathrm{ZnGa}_{2} \mathrm{O}_{4}$ single crystals, APL Mater. 7 (2019) 022512. https://doi.org/10.1063/1.5053867.

[39] D.C. Look, K.D. Leedy, R.-H. Horng, M.D. Santia, S.C. Badescu, Electrical and optical properties of degenerate and semi-insulating $\mathrm{ZnGa}_{2} \mathrm{O}_{4}$ : Electron/phonon scattering elucidated by quantum magnetoconductivity, Appl. Phys. Lett. 116 (2020) 252104. https://doi.org/10.1063/5.0014827.

[40] W.-K. Wang, K.-F. Liu, P.-C. Tsai, Y.-J. Xu, S.-Y. Huang, Influence of Annealing Temperature on the Properties of $\mathrm{ZnGa} 2 \mathrm{O} 4$ Thin Films by Magnetron Sputtering, Coatings. 9 (2019) 859. https://doi.org/10.3390/coatings9120859.

[41] H.J. Kim, I.C. Song, J.H. Sim, H. Kim, D. Kim, Y.E. Ihm, W.K. Choo, Electrical and magnetic properties of spinel-type magnetic semiconductor $\mathrm{ZnCo} 2 \mathrm{O} 4$ grown by reactive magnetron sputtering, $\mathrm{J}$. Appl. Phys. 95 (2004) 7387-7389. https://doi.org/10.1063/1.1688571.

[42] R. Pandey, J.D. Gale, S.K. Sampath, J.M. Recio, Atomistic Simulation Study of Spinel Oxides: Zinc Aluminate and Zinc Gallate, J. Am. Ceram. Soc. 82 (1999) 3337-3341. https://doi.org/10.1111/j.11512916.1999.tb02248.x.

[43] E. Chikoidze, C. Sartel, I. Madaci, H. Mohamed, C. Vilar, B. Ballesteros, F. Belarre, E. del Corro, P. Vales-Castro, G. Sauthier, L. Li, M. Jennings, V. Sallet, Y. Dumont, A. Pérez-Tomás, p-Type Ultrawide-Band-Gap Spinel $\mathrm{ZnGa}_{2} \mathrm{O}_{4}$ : New Perspectives for Energy Electronics, Cryst. Growth Des. 20 (2020) 2535-2546. https://doi.org/10.1021/acs.cgd.9b01669.

[44] A. De Vos, K. Lejaeghere, D.E.P. Vanpoucke, J.J. Joos, P.F. Smet, K. Hemelsoet, First-Principles Study of Antisite Defect Configurations in $\mathrm{ZnGa}_{2} \mathrm{O}_{4}$ :Cr Persistent Phosphors, Inorg. Chem. 55 (2016) 2402-2412. https://doi.org/10.1021/acs.inorgchem.5b02805.

[45] Y. Xia, T. Wang, X. Zhao, X. Jiao, D. Chen, Theoretical and Experimental Investigations on Effects of Native Point Defects and Nitrogen Doping on the Optical Band Structure of Spinel $\mathrm{ZnGa}_{2} \mathrm{O}_{4}$, J. Phys. Chem. C. 122 (2018) 5509-5517. https://doi.org/10.1021/acs.jpcc.7b12326.

[46] R.A. De Souza, D.N. Mueller, Electrochemical methods for determining ionic charge in solids, Nat. Mater. 20 (2021) 443-446. https://doi.org/10.1038/s41563-020-0790-9.

[47] A. Walsh, A.A. Sokol, J. Buckeridge, D.O. Scanlon, C.R.A. Catlow, Oxidation states and ionicity, Nat. Mater. 17 (2018) 958-964. https://doi.org/10.1038/s41563-018-0165-7.

[48] G. Greczynski, L. Hultman, X-ray photoelectron spectroscopy: Towards reliable binding energy referencing, Prog. Mater. Sci. 107 (2020) 100591. https://doi.org/10.1016/j.pmatsci.2019.100591.

[49] S. Geller, Crystal Structure of $\beta-G a 2 O 3$, J. Chem. Phys. 33 (1960) 676-684. https://doi.org/10.1063/1.1731237.

[50] D. Errandonea, R.S. Kumar, F.J. Manjón, V.V. Ursaki, E.V. Rusu, Post-spinel transformations and equation of state in $\$\{\mid \operatorname{text}\{\mathrm{ZnGa}\}\}_{-}\{2\}\{\mid \operatorname{text}\{\mathrm{O}\}\}_{-}\{4\} \$$ : Determination at high pressure by in situ $\mathrm{x}-$ ray diffraction, Phys. Rev. B. 79 (2009) 024103. https://doi.org/10.1103/PhysRevB.79.024103.

[51] R. Al-Gaashani, S. Radiman, A.R. Daud, N. Tabet, Y. Al-Douri, XPS and optical studies of different morphologies of $\mathrm{ZnO}$ nanostructures prepared by microwave methods, Ceram. Int. 39 (2013) $2283-$ 2292. https://doi.org/10.1016/j.ceramint.2012.08.075. 
[52] A.G. Marrani, F. Caprioli, A. Boccia, R. Zanoni, F. Decker, Electrochemically deposited ZnO films: an XPS study on the evolution of their surface hydroxide and defect composition upon thermal annealing, J. Solid State Electrochem. 18 (2014) 505-513. https://doi.org/10.1007/s10008-013-2281-2.

[53] S.B. Majumder, M. Jain, P.S. Dobal, R.S. Katiyar, Investigations on solution derived aluminium doped zinc oxide thin films, Mater. Sci. Eng. B. 103 (2003) 16-25. https://doi.org/10.1016/S09215107(03)00128-4.

[54] V. Kumar, H.C. Swart, O.M. Ntwaeaborwa, R.E. Kroon, J.J. Terblans, S.K.K. Shaat, A. Yousif, M.M. Duvenhage, Origin of the red emission in zinc oxide nanophosphors, Mater. Lett. 101 (2013) 57-60. https://doi.org/10.1016/j.matlet.2013.03.073.

[55] L.Q. Wu, Y.C. Li, S.Q. Li, Z.Z. Li, G.D. Tang, W.H. Qi, L.C. Xue, X.S. Ge, L.L. Ding, Method for estimating ionicities of oxides using O1s photoelectron spectra, AIP Adv. 5 (2015) 097210. https://doi.org/10.1063/1.4931996.

[56] J.-C. Dupin, D. Gonbeau, P. Vinatier, A. Levasseur, Systematic XPS studies of metal oxides , hydroxides and peroxides, Phys. Chem. Chem. Phys. 2 (2000) 1319-1324. https://doi.org/10.1039/A908800H.

[57] Z. Kabilova, C. Kurdak, R.L. Peterson, Observation of impurity band conduction and variable range hopping in heavily doped (010) $\beta-\mathrm{Ga}_{2} \mathrm{O}_{3}$, Semicond. Sci. Technol. 34 (2019) 03LT02. https://doi.org/10.1088/1361-6641/ab0150.

[58] W.-K. Wang, Y.-J. Xu, Huang, Liu, Tsai, Structural Characteristics and Photoluminescence Properties of Sputter-Deposition $\mathrm{ZnGa}_{2} \mathrm{O}_{4}$ Thin Films on Sapphire and $\mathrm{Si}(100)$ Substrates, Coatings. 9 (2019) 469. https://doi.org/10.3390/coatings9080469.

[59] S.K. Vasheghani Farahani, T.D. Veal, J.J. Mudd, D.O. Scanlon, G.W. Watson, O. Bierwagen, M.E. White, J.S. Speck, C.F. McConville, Valence-band density of states and surface electron accumulation in epitaxial $\$\{\backslash \operatorname{mathrm}\{\mathrm{SnO}\}\}_{-}\{2\} \$$ films, Phys. Rev. $\quad$ B. $90 \quad$ (2014) 155413. https://doi.org/10.1103/PhysRevB.90.155413.

[60] K.H.L. Zhang, R.G. Egdell, F. Offi, S. Iacobucci, L. Petaccia, S. Gorovikov, P.D.C. King, Microscopic Origin of Electron Accumulation in $\$\{\backslash \operatorname{mathrm}\{\operatorname{In}\}\}_{-}\{2\}\{\backslash \text { mathbf }\{O\}\}_{-}\{3\} \$$, Phys. Rev. Lett. 110 (2013) 056803. https://doi.org/10.1103/PhysRevLett.110.056803.

[61] E. Chikoidze, D.J. Rogers, F.H. Teherani, C. Rubio, G. Sauthier, H.J.V. Bardeleben, T. Tchelidze, C. Ton-That, A. Fellous, P. Bove, E.V. Sandana, Y. Dumont, A. Perez-Tomas, Puzzling robust 2D metallic conductivity in undoped $\beta-\mathrm{Ga} 2 \mathrm{O} 3$ thin films, Mater. Today Phys. 8 (2019) 10-17. https://doi.org/10.1016/j.mtphys.2018.11.006.

[62] M. Gu, S.A. Wolf, J. Lu, Two-Dimensional Mott Insulators in SrVO3 Ultrathin Films, Adv. Mater. Interfaces. 1 (2014) 1300126. https://doi.org/10.1002/admi.201300126.

[63] J. Halim, M.R. Lukatskaya, K.M. Cook, J. Lu, C.R. Smith, L.-Å. Näslund, S.J. May, L. Hultman, Y. Gogotsi, P. Eklund, M.W. Barsoum, Transparent Conductive Two-Dimensional Titanium Carbide Epitaxial Thin Films, Chem. Mater. 26 (2014) 2374-2381. https://doi.org/10.1021/cm500641a. 
[64] M. Nistor, F. Gherendi, N.B. Mandache, C. Hebert, J. Perrière, W. Seiler, Metal-semiconductor transition in epitaxial $\mathrm{ZnO}$ thin films, J. Appl. Phys. $106 \quad$ (2009) 103710. https://doi.org/10.1063/1.3259412.

[65] W. Noun, B. Berini, Y. Dumont, P.R. Dahoo, N. Keller, Correlation between electrical and ellipsometric properties on high-quality epitaxial thin films of the conductive oxide LaNiO3 on STO (001), J. Appl. Phys. 102 (2007) 063709. https://doi.org/10.1063/1.2781517.

[66] Y.-S. Kim, C.H. Park, Rich Variety of Defects in $\mathrm{ZnO}$ via an Attractive Interaction between O Vacancies and Zn Interstitials: Origin of n -Type Doping, Phys. Rev. Lett. 102 (2009) 086403. https://doi.org/10.1103/PhysRevLett.102.086403.

[67] X. Zhang, A. Zunger, Diagrammatic Separation of Different Crystal Structures of A2BX4 Compounds Without Energy Minimization: A Pseudopotential Orbital Radii Approach, Adv. Funct. Mater. 20 (2010) 1944-1952. https://doi.org/10.1002/adfm.200901811.

[68] B.I. Shklovskii, A.L. Efros, Electronic Properties of Doped Semiconductors, Springer Science \& Business Media, 1984.

[69] P.W. Anderson, Absence of Diffusion in Certain Random Lattices, Phys. Rev. 109 (1958) 1492-1505. https://doi.org/10.1103/PhysRev.109.1492.

[70] T. Ying, Y. Gu, X. Chen, X. Wang, S. Jin, L. Zhao, W. Zhang, X. Chen, Anderson localization of electrons in single crystals: $\mathrm{Li} \quad{ }_{x} \quad \mathrm{Fe} 7 \mathrm{Se}$ 8, Sci. Adv. 2 (2016) e1501283. https://doi.org/10.1126/sciadv.1501283.

[71] E. Chikoidze, Y. Dumont, E. Popova, N. Keller, A. Shumilin, V. Kozub, B. Warot-Fonrose, Large Room Temperature Magneto-Resistance in Magnetically Disordered

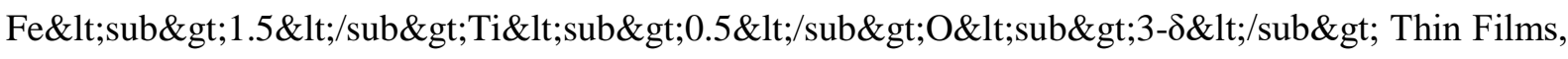
World J. Condens. Matter Phys. 04 (2014) 250-261. https://doi.org/10.4236/wjcmp.2014.44028.

[72] E. Chikoidze, H.J. von Bardeleben, K. Akaiwa, E. Shigematsu, K. Kaneko, S. Fujita, Y. Dumont, Electrical, optical, and magnetic properties of Sn doped $\alpha-\mathrm{Ga}_{2} \mathrm{O}_{3}$ thin films, J. Appl. Phys. 120 (2016) 025109. https://doi.org/10.1063/1.4958860. 